\title{
A HUNDRED YEARS OF PLANT MORPHOLOGY*
}

\author{
By DR. H. HAMSHAW THOMAS, F.R.S.
}

\begin{abstract}
N 1851 British botanists were still mainly occupied with the description and classification of plants, studies which were very similar to those which had been carried on since the days of William Turner in the sixteenth century. The work of men like Grew, Hales, Bradley and Knight, who realized the interest of plant physiology and plant biology, had exerted little influence on the main current of botanical thought; in fact, these men were not generally regarded as botanists. Botany was studied only in the field, the garden and the herbarium; botanical laboratories did not exist, and teachers like Henfrey and John Hutton Balfour (known to his students as "old woody fibre"), who attempted to develop anatomical study with the aid of the microscope, had met with little success.
\end{abstract}

At the time of the Exhibition of 1851, many of the outstanding botanists of the early nineteenth century were still living. Robert Brown, in his seventy-eighth year, was president of the Linnean Society; Sir William Hooker was director of the Royal Botanic Gardens, Kew ; John Lindley was professor in University College, London; J. S. Henslow, Darwin's teacher, still held the chair of botany at Cambridge but was also rector of Hitchin and only resided in Cambridge during the Easter term; Sir Joseph Hooker had just returned home from his Himalayan journey, and Charles Darwin was quietly working at Downe on Cirripedes and brooding over the 'species question'. Modern botany was being actively developed in Germany by von Mohl, Nägeli, Hofmeister and others who had been stimulated by Schleiden; but it had very little influence in Britain. It is remarkable that there is no reference in the "Origin of Species", the letters of Charles Darwin or the published letters of Sir Joseph Hooker, to Hofmeister's "Comparative Researches on the Higher Cryptogams and Gymnosperms" which was published in 1851, and demonstrated the existence of an alternation of generations in these two groups-a powerful argument for the idea of evolution. This work was, however, translated into English and published by the Ray Society in $\mathbf{1 8 6 2 .}$

The outlook on plant structure in 1851 was that commonly held before the coming of the doctrine of evolution. Each species was believed to be the result of a separate act of creation; it had a form and structure which distinguished it from other plants. But among the great diversity of form it was possible by the exercise of the mind to recognize certain unifying principles. A mental picture of an ideal plant might be formed to serve as a standard with which all actual living forms could be compared. Goethe and the German Nature philosophers of the early nineteenth century formulated different concepts of the ideal plant, but Goethe's was the only one of lasting value. This was an imaginary organism consisting of a stem bearing a series of leaves showing various types of metamorphosis, or conceptual change, and having roots below the ground. Goethe's new science of morphology made considerable progress. We find Lindley expounding it in 1832 in his "Intro-

* Substance of a paper entitled "Changes in the Outlook on Plant Structure during the Past Hundred Years" read on August 9 before Section K (Botany) at the Edinburgh meeting of the British Association. duction to Botany". In 1857 Henfrey, in his "Elementary Course of Botany", writes: "the study of the metamorphosis of the organs of the flower is now advanced far enough to set all general questions at rest". Although his treatment of morphology and comparative anatomy is mainly descriptive, Henfrey defined this branch of botany as having the object of ascertaining what are the elements of plant organs, and of tracing out the laws under which they acquire the different forms presented in fully developed plants.

The publication of "The Origin of Species" in 1859 gave a new impetus and a change of direction to the comparative study of plant form. While Darwin himself did not claim that the parts of flowers had arisen in evolution from leaves of a uniform type, he mentioned that "almost everyone is familiar with the view that the floral parts are metamorphosed leaves". At first there seems to have been no change in botanical studies; but a great revolution in the outlook of botanists took place between 1870 and 1880.

The leaven of the concepts of evolution, the work of the great German plant scientists, the genius and energy of Prof. T. H. Huxley, the Education Bill of 1870 passed by Gladstone's Liberal Government, all combined to produce far-reaching results. Huxley had been teaching in South Kensington in buildings resulting from the 1851 Exhibition, and he undertook the organization of classes in biology to train teachers in science for the new public elementary schools. These classes included adequate practical work, an innovation in Britain at the time. Studies of a taxonomic kind were subordinated to the teaching of anatomy, physiology and the life-histories of plants. Thiselton-Dyer gave the first course in botany in 1873 , assisted by Lawson of Oxford, Vines came from Cambridge as an assistant in 1875, and later Hillhouse, Daniel Morris and Bower took part in the teaching. Before long, teaching with laboratory work on the same pattern was begun in several British universities. Lawson began at Oxford, Vines, although not holding the chair, organized classes at Cambridge, Hillhouse went to Birmingham, and Bower to Glasgow. Dyer played a large part in the foundation of the Jodrell Laboratory at Kew, where much important work in plant morphology and physiology has been carried out.

The establishment of the Normal College of Science, which later became the Imperial College of Science and Technology, was a very important event in the history of botany in Britain. It produced a small band of enthusiastic teachers and investigators, two of them responsible for my own interest in botany, and it led to considerable activity in the investigation of plant form and structure.

At the outset, the exponents of the new botany concentrated on the objective study of all aspects of plant life. The great text-book by Sachs was translated into English and published in 1875. It contained little morphological theory; but plant structure was treated in some detail with frequent reference to the development of organs and their physiological implications. This book aided the new movement. But very soon the minds of biologists began to be influenced more and more by the ideas of 
evolution, and the establishment of phyletic relationships became one of the chief endeavours of many British botanists.

Between the years 1880 and 1910 the study of plant structure was dominated by the belief that it held the key to the problems of phylogeny. Attention was mainly paid to the Pteridophyta and Gymnosperms, the possible connexion of which had been indicated by the work of Hofmeister. This climate of thought was intensified by the striking discoveries in Britain of fossil plants with well-preserved structure. These were especially due to W. C. Williamson, who was appointed professor of natural history in Owen's College, Manchester, on its foundation in 1851 . Between 1868 and 1895 he described the structural details of many interesting and novel forms from the nodules of the coal measures of Lancashire and Yorkshire, and showed how some ancient pteridophytes were trees with secondary thickening. This and other contemporary work directed attention to the importance of this group in the vegetation of ancient times, while the structure of the stems called Lyginopteris and Heterangium suggested a connexion between the ferns and cycads.

All this historical evidence of evolution based on anatomical structure made a profound impression on the younger botanists of the time and many of them became active investigators. D. H. Scott, who was keeper of the Jodrell Laboratory, became associated with Williamson and afterwards continued to describe the structure of fossil plants ; Kidston as an amateur began his detailed investigation of the Carboniferous plants of Scotland ; Seward studied with Williamson at Manchester, and then specialized on the plants of the Mesozoic period; Oliver, working with Scott, established the characteristics of the Pteridosperms, and later added greatly to our knowledge of fossil gymnosperm seeds. At the same time, our knowledge of the living pteridophytes was being greatly extended, especially by Bower, who devoted his long life to the investigation of this group.

It would be difficult to exaggerate the importance of this period in the acquisition of factual knowledge, though the general trend of thought of the time is open to criticism from the philosophical aspect. For some twenty-five years it was assumed that Goethe's morphology could be forced into an evolutionary frame. As Dr. Agnes Arber so aptly writes, "by a feat of legerdemain, which seems to have passed almost unnoticed, the Ancestral Plant was substituted for the Archetypal Plant and those characters which had, with reason, been attributed to the mental conception of the archetype were, without further justification, assumed to have been proven for an actual historically existent ancestor". This point of view was encouraged among botanical students in Britain by the earlier translations of Strasburger's "Text-book of Botany". For a long time it proved a real stumbling block to the understanding of the fossil record, as well as creating an unbridgeable gulf between the Thallophyta and the Cormophyta.

The preoccupation of British botanists with the cryptogams and gymnosperms led to the realization of the value of anatomical characters in the study of plant morphology, a view that was regarded as heretical by the German botanists. It resulted, however, in considerable neglect of the flowering plants. Before 1920 almost the only extensive series of investigations in this group was the study of seedling structure under the leadership of Dr. Ethel Sargant. At first the aim of this work seems to have been mainly phylogenetic, but as it progressed Hill and De Fraine, and also Compton, were led to recognize the importance of physiological and ecological considerations.

The growth of the study of ecology, genetics and cytology towards the end of the first decade of this century diverted the attention of many young botanists from the pursuit of phyletic morphology. These subjects, as well as physiology and physiolo. gical anatomy, caused the problems of plant structure to appear in a new light. Bower's great book on "The Origin of a Land Flora" (1908) introduced biological considerations into morphological discus. sion and thus initiated a break with tradition; hitherto plant anatomy and morphology had been completely separated from physiological considerations.

From this time onwards there was in Britain a steady weakening of the view, expressed in Strasburger's textbook, that phylogeny is the only real basis of morphological study. This dictum was severely handled by Prof. W. HI. Lang in his address to Section $\mathrm{K}$ of the British Association in 1915. He advocated a wider view of the significance of plant structure gained from the study of parallel developments, the methods of advance in different groups and in different generations of the life-cycle, the changes observable during development and the results of experimental treatment. Though this causal outlook is essentially different from the historical outlook, there is no opposition between causal and phyletic morphology. It has to be recognized that "there has been an evolution, not of mature plants, but of specific substances exhibiting development". Owing to the First World War, this admirable address probably received less attention than it deserved. A few years later Kidston and Lang published their full account of the plants of the Rhynie Chert, and opened up new lines of thought on plant evolution. They described very early plants which were completely different from the Urform of Goethe ; and Lang's later work on the Silurian and early Devonian forms, together with that of Halle, Krausel and Weyland, showed that these forms were typical of the early cormophytes.

At the meeting of the British Association in Edinburgh in 1921, Dr. D. H. Scott as president discussed the phyletic implications of the recent discoveries in the Rhynie Chert, while Prof. Bower developed the causal side by a very interesting paper on size and form. Some of us who were present felt that, from these two aspects of morphology, real progress was being made; but the great problem was the bearing of this new knowledge on the morphological study of the flowering plants.

It seemed to me in 1932 that we should make no progress until we recognized clearly that Goethe's concept of metamorphosis had no evolutionary significance: for this reason I suggested that a fundamental distinction existed between the old morphology and the new. But this opinion has gained adherents very slowly. In the period between 1925 and 1939 Miss F. R. Saunders carried out a series of researches on the vascular structure of angiosperm flowers with the view of elucidating the evolution of carpels. While adding considerably to our factual knowledge, the value of her conclusions depends on the validity of her premises, and it seems doubtful if her basic suppositions were justified from a historical point of view. On the other hand, the work of Dr. Agnes Arber shows that most valuable results are forthcoming by strict adherence to the philosophical system of the old morphology. Many 
people now find this approach to the study of form difficult to understand owing to our changed outlook on natural objects. They may have read papers like the admirable address on the interpretation of plant structure delivered to Section $\mathrm{K}$ of the British Association in 1939 by Prof. D. Thoday, and cannot envisage a system of thought from which biological and physiological considerations are excluded.

A survey of the changes in outlook since 1851 seems to show that form and structure can be viewed from three separate aspects : the old, abstract and purely intellectual approach ; the causal and developmental point of view : the objective and historical study of plant evolution, which is, perhaps, still undeveloped as a logical system of thought. While these three branches of study will probably be best developed as separate disciplines, I believe that their results will eventually contribute to a synthesis of far-reaching importance.

\section{GEOGRAPHY IN THE SERVICE OF MANKIND*}

By E. O. GIFFARD, M.B.E.

$\mathrm{A}$ LAYMAN is not the right person to review the academic evolution of geography or to put forward detailed proposals for its further development as a scientific study : such matters must be left to those properly qualified to deal with them. A layman, however, may quite properly examine the record of the services of gengraphy to the common people, and, indeed, may also be a proper person to urge that geographical knowledge shall be more frequently and widely applied in the conduct of both national and international affairs.

It is commonly said that 'pure' scientists are not concerned with or about the use made of the knowledge which they accumulate. Results, in their case, are said to be sufficient if it can be proved that something has been added to the store of human knowledge. This familiar argument is, of course, basically sound; but it appears to overlook the fact that, in the last analysis, a man of science is a specialist or expert employed in the service of his fellow-men. That is to say, he is, directly or indirectly, a servant of the public. Now the public is accustomed to assess the value of any study or activity by an analysis of its observed or deduced results. If the results appear to be good, then the study or activity in question continues to command respect and support and the specialists and experts concerned enjoy a high reputation. If, on the other hand, the results appear to be unsatisfactory or if, after a reasonable time, no results can be seen or deduced, then the value of the particular study or activity becomes suspect and the support accorded to its practitioners is liable to be diminished. For these reasons it is submitted that men of science and particularly geographers cannot afford to remain entirely disinterested in the use made of their knowledge and ought to do whatever they can to encourage its useful application.

As has been said, the public tends to evaluate a study or activity by its visible, demonstrable or deducible results. In this connexion the words 'visible and demonstrable' are particularly important.

* Substance of a paper read on August 10 before Section $\mathbf{F}_{\text {(Geo- }}$ graphy) at the Edinburgh mecting of the British Association.
Remember the wisdom of those who insisted that justice must not only be done but must "manifestly be done". If public respect for scientific work is to be maintained at a high level and if financial support is to be forthcoming on an adequate scale, then the results of such work must be manifest. In this connexion the increasing dependence of our universities upon the public purse is not to be forgotten.

Results sufficient for the purpose need not, however, be directly produced by those who accumulate the required knowledge. It will serve well enough if they are usually produced by laymen who know how to use the knowledge or the techniques supplied by the professional experts, provided always that the experts receive adequate credit for the vital part they have played.

Compared with many other scientific workers or experts, the geographer is somewhat handicapped in the matter of producing visible or demonstrable results. The physicist, for example, lacks no publicity for the results of his labours, nor does the chemist or the engineer. The geographer, however, like the economist or the psychologist, deals largely in ideas which can rarely, if ever, be translated into anything which can be seen except upon paper. Perhaps he is a little better off than the economist and certainly he is better off than the psychologist, because the geographer at least has the solid earth as the subject of his study, whereas the psychologist is concerned with the invisible and intangible thought processes of the human brain. Nevertheless, the geographer creates few visible evidences of his work and it is not often possible for the layman to pause and point and say "that was done by a geographer".

Since geographers are not, in the ordinary sense of the words, either producers or administrators, since they do not till the soil, fish the seas, labour directly in industry, engage in trade or direct the energies of those who do these things, their contribution to the common effort and the common weal has to consist, on one hand, of learning and recording things about the earth as the home of man and, on the other, of teaching and advising. For visible results the layman has to be content with books and maps and things on paper : for other results he must rely on deduction rather than sight. In other words, he must look for abstract rather than concrete evidence. Naturally enough, he thinks of the geographer (when he thinks of him at all) as the informer, teacher or adviser, and he thinks he ought to be able to detect the influence of the geographer in many departments of human affairs. Nor is it unreasonable that he should do so. As practitioners of a subject which can claim no less than twenty-one academic chairs in Great Britain alone, as intellectuals equipped with special knowledge about the home of man, geographers ought surely to be found exerting a profound influence on the conduct of both national and international affairs. What are the facts ?

Outside the universities and the schools, geographers are held to be of small account. In the departments of State, in local government, in industry and commerce and in the Fighting Services they are almost unknown. That surely must be very disappointing, if not humiliating, to professional geographers. Certainly it is a thought-provoking fact to laymen. Admittedly geographers have served on one Royal Commission (the Royal Commission on the Geographical Distribution of Industry) and may have served on others though not specifically as geographers. Some have served on the staff of the 